\title{
Psychosocial Health Level and Quality of Sexual Life in Women with Fibrocystic Breast Disease
}

\author{
Kadriye Aldemir ${ }^{*}$, Aysel Gurkan ${ }^{2}$, Feride Taskin Yilmaz ${ }^{1}$, Sevinc Kaymaz ${ }^{3}$ and Gulbahtiyar Demirel ${ }^{4}$
}

${ }^{1}$ Department of Nursing, Suşehri School of Health, Cumhuriyet University, Sivas, Turkey

${ }^{2}$ Department of Nursing, Faculty of Health Sciences, Marmara University, Istanbul, Turkey

${ }^{3}$ Liv Hospital, Istanbul, Turkey

${ }^{4}$ Department of Midwifery, Faculty of Health Sciences, Cumhuriyet University, Sivas, Turkey

*Corresponding author: Kadriye Aldemir, Department of Nursing, Suşehri School of Health, Cumhuriyet University, 58140 Sivas, Turkey, Tel: +90-346-311-52-23/107, Fax:+90-346-2191260, E-mail: kadriyealdemir86@hotmail.com

\begin{abstract}
Objective: Anxiety about the fibrocystic disease of breast and the formation of cancer can lead to some psychosocial and sexual health problems in women. In this context, this study was conducted to determine the level of depression and sexual life quality of women with fibrocystic disease of breast.

Methods: The sample of this descriptive study consisted of 40 women with fibrocystic breast disease and 50 without fibrocystic breast disease and who agreed to participate in the study. Data were collected using the individual diagnostic form, the Depression Anxiety Stress Scales (DASS) and the Sexual Life Quality Questionnaire (SLQQ). Data obtained from the study were interpreted in the SPSS 23.0 package program. Mean, standard deviation, percentage distribution, the student t-test, chi-square test, Pearson correlation analysis, Mann-Whitney $\mathrm{U}$ test, and the Kruskall Wallis test were used in the statistical evaluation. Statistical significance was accepted as $p<0.05$.

Results: Women with fibrocystic disease of breast were found to have an advanced depression, an advanced anxiety, and a moderate level of stress. Women with fibrocystic disease of breast were found to have statistically higher levels of depression, anxiety and stress than women without the disease $(p<0.01)$. Women with fibrocystic disease of breast were found to have a moderate level of sexual life quality, and statistically significantly lower sexual life quality than women without the disease $(p<0.01)$.

Conclusion: Women with fibrocystic of breast was lower levels of psychosocial health and sexual life quality than those without fibrocystic breast disease.
\end{abstract}

\section{Keywords}

Sexuality, Fibrocystic breast, Psychosocial, Life quality

\section{Introduction}

The most common benign histopathologic changes of the breast are fibrocystic changes. Although the prevalence of fibrocystic change in the population is not known precisely, it is reported that about $30-35 \%$ of women between the ages of 20-45 have been detected changes [1]. The fibrocystic change of the breast is an indeterminate mass in the breast and a mass characterized by nodularity in the breast, usually accompanied by pain and sensitivity [2]. Fibrocystic diseases of breast are not at high risk for breast cancer, but studies have shown that women who have breast symptoms experience similar psychosocial problems to women who have breast cancer [3,4]. Some women experience lower anxiety and stress levels after a diagnosis of benign breast disease, while some women continue to experience distress $[5,6]$. A study of women participating in breast cancer screening has shown that women's perceived susceptibility to breast cancer is high despite a normal mammogram [7]. The reason for this is that the women are not confident about the diagnosis or that the health professionals do not reassure about breast health [8]. Any medical interventions, routine examinations and follow-ups to women after the diagnosis of fibrocystic disease of breast can affect the psychosocial well-being of women.

Although there is extensive literature on the effect of breast cancer on sexuality, there are no studies of

Citation: Aldemir K, Gurkan A, Yilmaz FT, Kaymaz S, Demirel G (2018) Psychosocial Health Level and Quality of Sexual Life in Women with Fibrocystic Breast Disease. Int J Womens Health Wellness 4:069. doi.org/10.23937/2474-1353/1510069

Received: April 16, 2018: Accepted: May 10, 2018: Published: May 12, 2018

Copyright: (c) 2018 Aldemir K, et al. This is an open-access article distributed under the terms of the Creative Commons Attribution License, which permits unrestricted use, distribution, and reproduction in any medium, provided the original author and source are credited. 
women with fibrocystic disease of breast. However, sexuality is a phenomenon related to physiological, psychological and social factors $[9,10]$ and sexual health can be affected by many factors such as chronic diseases, pain, psychosocial health problems, body image changes [11].

In this context, the research was conducted to compare the levels of psychosocial health and quality of sexual life in women with and without fibrocystic breast disease.

\section{Methods}

\section{Research type}

The research was conducted descriptively and crosssectionally.

\section{Method}

The population of the study consisted of 48 women who applied for follow-up due to fibrocystic breast disease to a special hospital's radiology polyclinic in Istanbul, Turkey between 01-30 September 2017, who had a history of fibrocystic breast disease for at least one year, aged 18 years and over, who did not go through the menopause, who had no psychiatric disease, or did not use psychotropic medication, and who had mental competence to understand and apply the data collection forms. The sample of the study included 40 women who agreed to participate in the study.

The level of psychosocial health and sexual life quality of women with fibrocystic breast disease was compared using a control group formed by relatives of the patients. In this direction, the control group consisted of 50 women who were 18-years-old or older from the relatives of the women who applied to the radiology clinic, does not have any breast disease in herself or in close relatives, did not go through the menopause, did not have a psychiatric diagnosis, or did not use psychotropic medication yet, had mental competence to understand and apply the data collection forms and participated voluntarily created this population.

\section{Data collection tools}

Data were collected using the individual identification form, Depression, Anxiety, Stress Scale and Sexual Quality of Life Questionnaire.

Individual identification form: The form created by the researchers consists of 12 questions and contains sociodemographic characteristics.

Depression, Anxiety, Stress Scale (DASS): The scale used to assess the psychosocial health level was developed by Lovibond and Lovibond in 1995 and adapted to Turkish by Akin and Cetin and validity and reliability study was done. Scale has a 4-point Likert-type rating of 0 "not at all suitable to me", 1 "a little suitable to me", 2 "generally suitable to me", and 3 "completely suitable
Table 1: DASS scoring.

\begin{tabular}{|l|l|l|l|}
\hline & $\begin{array}{l}\text { Depression sub- } \\
\text { dimension }\end{array}$ & $\begin{array}{l}\text { Anxiety sub- } \\
\text { dimension }\end{array}$ & $\begin{array}{l}\text { Stress sub- } \\
\text { dimension }\end{array}$ \\
\hline Normal & $0-9$ & $0-7$ & $0-14$ \\
\hline Mild & $10-13$ & $8-9$ & $15-18$ \\
\hline Moderate & $14-20$ & $10-14$ & $19-25$ \\
\hline Severe & $21-27$ & $15-19$ & $26-33$ \\
\hline Very severe & $28+$ & $20+$ & $34+$ \\
\hline
\end{tabular}

to me". There are a total of 42 items in the DASS, 14 of which are depression, 14 of which are anxiety and 14 of which are stress sub-dimensions. Depression, anxiety and stress levels according to the average score obtained in each subscale are evaluated according to the scoring as follows. In the study, the Cronbach Alpha internal consistency coefficient of the DASS was 0.94, 0.90 for the depression subscale, 0.91 for the anxietysubscale, and 0.87 for the stress subscale [12] (Table 1).

Sexual Quality of Life-Female Questionnaire (SQLQ-F): The questionnaire developed by Symonds, et al. and validity and reliability study done by Tugut and Golbasi in Turkey is applied to women over the age of 18 . The scale is of the six-point likert type and consists of 18 items. It is expected that each item to be answered by considering the sexual life in the last four weeks. Each item is scored between 1 and 6 on the scale ( 1 = strongly agree, $2=$ considerably agree, 3 = partially agree, 4 = partially disagree, $5=$ considerably disagree, 6 = strongly disagree). The range of scores that can be taken from this scale varies between 18-108. In this scoring system, the total score from the scale is converted to 100 . In order to convert the total scale score to 100, (Raw score taken from the scale-18) $\times 100 / 90$ formula must be used. The high score from the scale indicates that the quality of sexual life is good. In this study, the cronbach alpha reliability coefficient of the scale was 0.81 [13].

Application: The data were collected by the researchers face-to-face in a separate empty room or in an environment where they could meet each woman in order to protect their privacy. The researchers informed the women about the purpose and the importance of the study, and the individual identification form and the DASS were applied one-to-one to the women who agreed to participate in the study, and they were made to fill in the sexual quality of life questionnaire on their own in order to be able to answer them comfortably. Study forms took 2025 minutes to fill out by the individuals.

Ethical aspect: A written consent was obtained from the ethics committee of a university (Decision no. 201602/02) before the data were collected. In addition, every woman to be involved in the study was informed verbally about the content of the study and the voluntary participation and the written approval of the women was taken.

Evaluation of the data: The data were interpreted in the SPSS 22.0 package program. Mean, standard deviation and percentage distribution were used in the 
distribution of demographic and disease related characteristics of women. In the comparison of the descriptive characteristics of women with and without fibrocystic breast disease, t-test and Chi-square test were used in independent groups, Fisher's Exact test and t-test were used in the ones with frequency value below 5 , t-test was used to compare the mean scores of DASS and SQLQ-F questionnaire in independent groups. In order to determine the relationship between the descriptive characteristic and scores of DASS and SQLQ-F questionnaire of the women with fibrocystic breast disease, Pearson correlation analysis, Mann-Whitney $U$ test, and the Kruskall Wallis test were used. Statistical significance was assessed at $p<0.05$.

\section{Limitations of the research}

The study included sampling and time limitations as it was done with women who applied to the radiology clinic of a single hospital in a limited time and met the criteria for inclusion. In this context, the results of the study can not be generalized to women with all fibrocystic breast disease. In addition, self-reports of psychosocial health and sexual life quality of women were limited to DASS and SQLQ-F questionnaire, and the patients who came for the examination. In future studies, there is a need to study psychosocial health levels and quality of sexual life in women with fibrotic breast disease with wider sample group.

\section{Results}

The distribution of sociodemographic characteristics of women with and without fibrocystic breast disease is given in Table 2. According to this, it was found that there was a statistically significant difference between the women with and without fibrocystic breast disease in terms of working status, smoking habits, age of menarche, birth status, and family history of breast disease $(p<0.01)$. In this context, it was determined that women with fibrocystic breast disease had high rates of working, smoking and family history of breast disease, the mean age of menarche is higher and low birth rates.

Table 3 presents a comparison of the mean scores of DASS and SQLQ-F questionnaire for women with and without fibrocystic breast disease. According to this, the mean score of depression subscale of the women with fibrotic breast disease was $23.05 \pm 7.39$ and they were severely depressed, the mean score of anxiety subscale was $21.95 \pm 8.07$ and they were very severely anxious and the mean score of stress subscale was $22.90 \pm 7.49$ and they experienced moderate stress. Women with fibrocystic breast disease were found to have higher levels of depression, anxiety and stress than women without fibrocystic breast disease $(p<0.01)$.

The level of sexual quality of life of women with fibrocystic breast disease $(50.30 \pm 9.47)$ was found to be moderate and the level of sexual quality of life was

Table 2: Some sociodemographic characteristics of women $(N=90)$.

\begin{tabular}{|c|c|c|c|}
\hline Characteristics & $\begin{array}{l}\text { Women with fibrocystic breast } \\
\text { disease n (40)\% }\end{array}$ & $\begin{array}{l}\text { Women without fibrocystic } \\
\text { breast disease n }(50) \%\end{array}$ & $X^{2} / p$ \\
\hline Age (year) $(\mathrm{M} \pm \mathrm{SD})$ & $\begin{array}{l}37.85 \pm 8.38 \\
(\min =22, \max =52)\end{array}$ & $\begin{array}{l}36.54 \pm 8.58 \\
(\min =24, \max =56)\end{array}$ & $t=1.295 / 0.199$ \\
\hline \multicolumn{4}{|l|}{ Marital status } \\
\hline Married & $40(100)$ & $47(94.0)$ & \multirow{2}{*}{$2.483 / 0.251$} \\
\hline Single & $0(0)$ & $3(6.0)$ & \\
\hline \multicolumn{4}{|l|}{ Working status } \\
\hline Yes & $22(55.0)$ & $14(28.0)$ & \multirow{2}{*}{$6.750 / 0.017^{*}$} \\
\hline No & $18(45.0)$ & $36(72.0)$ & \\
\hline \multicolumn{4}{|l|}{ Smoking status } \\
\hline Current smoker & $21(52.5)$ & $10(20.0)$ & \multirow{3}{*}{$14.163 / \mathbf{0 . 0 0 1}^{*}$} \\
\hline Ex-smoker & $6(15.0)$ & $4(8.0)$ & \\
\hline Never smoker & $13(32.5)$ & $36(72.0)$ & \\
\hline Menarche age (year) $(\mathrm{M} \pm \mathrm{SD})$ & $\begin{array}{l}14.35 \pm 1.90 \\
(\min =12, \max =18)\end{array}$ & $\begin{array}{l}13.56 \pm 1.14 \\
(\min =12, \max =16)\end{array}$ & $t=2.437 / 0.017^{\star}$ \\
\hline \multicolumn{4}{|l|}{ Birth status } \\
\hline Yes & $27(67.5)$ & $47(94.0)$ & \multirow[t]{2}{*}{$10.676 / 0.002^{*}$} \\
\hline No & $13(32.5)$ & $3(6.0)$ & \\
\hline \multicolumn{4}{|l|}{ Use of contraception } \\
\hline Yes & $24(60.0)$ & $35(70.0)$ & \multirow[t]{2}{*}{$0.984 / 0.375$} \\
\hline No & $16(40.0)$ & $15(30.0)$ & \\
\hline \multicolumn{4}{|l|}{ Family history of breast disease } \\
\hline Yes & $16(40.0)$ & $0(0)$ & \multirow[t]{2}{*}{$24.374 / 0.000^{*}$} \\
\hline No & $24(60.0)$ & $50(100)$ & \\
\hline $\begin{array}{l}\text { The duration of fibrocystic breast } \\
\text { disease (year) }(M \pm S D)\end{array}$ & $\begin{array}{l}3.22 \pm 2.28 \\
(\min =1, \max =10)\end{array}$ & & \\
\hline
\end{tabular}


Table 3: Correlation of Depression, Anxiety, Stress Scale and Sexual Quality of Life-Female Questionnaire Score Averages in women.

\begin{tabular}{|c|c|c|c|c|c|c|}
\hline \multirow{2}{*}{ Scales } & \multirow{2}{*}{$\begin{array}{l}\text { Range of } \\
\text { obtainable } \\
\text { scores } \\
\text { (min-max) }\end{array}$} & \multicolumn{2}{|c|}{$\begin{array}{l}\text { Women with fibrocystic breast } \\
\text { disease }\end{array}$} & \multicolumn{2}{|c|}{$\begin{array}{l}\text { Women without fibrocystic breast } \\
\text { disease }\end{array}$} & \multirow{2}{*}{$t / p$} \\
\hline & & $\begin{array}{l}\text { Range of scores } \\
\text { obtained (min-max) }\end{array}$ & $M \pm S D$ & $\begin{array}{l}\text { Range of scores } \\
\text { obtained (min-max) }\end{array}$ & $M \pm S D$ & \\
\hline \multicolumn{7}{|l|}{ DASS } \\
\hline Depression & $0-42$ & $10-37$ & $23.05 \pm 7.39$ & $1-25$ & $8.70 \pm 6.26$ & $9.964 / 0.000^{*}$ \\
\hline Anxiety & $0-42$ & $9-38$ & $21.95 \pm 8.07$ & $1-26$ & $9.10 \pm 6.15$ & $8.562 / 0.000^{*}$ \\
\hline Stress & $0-42$ & $11-38$ & $22.90 \pm 7.49$ & $2-33$ & $13.70 \pm 7.92$ & $5.604 / 0.000^{*}$ \\
\hline SQLQ-F & $0-100$ & $21-71$ & $50.30 \pm 9.47$ & $61-92$ & $78.96 \pm 10.93$ & $-11.404 / 0.000$ \\
\hline
\end{tabular}

" $p<0.01$.

found to be statistically significantly lower than that of women without fibrocystic breast disease $(p<0.01)$.

In Table 4, the relationship between the descriptive characteristic and Depression, Anxiety, Stress Scale and Sexual Quality of Life-Female Questionnaire Score in women with fibrocystic breast disease was given. Accordingly, it was determined that the age, working status, smoking status, menarche age and delivery status of the women with fibrocystic disease of breast did not affect psychosocial health level and sexual life quality ( $p$ $>0.05$ ), but the duration of fibrocystic disease of breast affected psychosocial health and sexual life quality negatively ( $p<0.05$ ). In addition, women with fibrocystic disease of breast using contraceptives were found to have higher levels of depression than those who did not $(p<0.05)$ (Table 4).

\section{Discussion}

Fibrocystic breast disease is a condition that disrupts the individual's comfort in both physical and psychosocial aspects. Routine controls, pain and tenderness caused by hormonal changes in the premenstrual period [1], concerns about prospective breast health can disrupt psychosocial well-being in women. In a study to compare the psychosocial health status of women with and without fibrocystic breast disease, it was determined that depression, anxiety and stress levels in women with fibrocystic breast disease were higher than women without breast disease. This study finding is similar to the results of previous studies with women with benign breast disease. In a study of Eskelinen, et al. comparing the anxiety levels of women with malign and benign breast disease and healthy women, it was reported that anxiety levels of women with benign breast disease were lower than those of malign breast disease and higher than that of healthy women. In the same study, women without breast problems were found to be happier and more outgoing [14]. Another study comparing cancer concerns of healthy women and women with benign breast disease found that women with benign breast disease had more concerns about breast cancer $[15,16]$. In a study conducted with women with benign breast disease in China, the prevalence of anxiety and depression in women was $40.2 \%$ and $62.0 \%$, respectively, and anxiety and depression levels were found to be higher than the general population. In the same study, it was determined that anxiety and depression symptoms affected physical and psychological quality of life of women quite negatively [17]. Keyzer, et al. assessed the depression levels of women who were taking mammograms for the first time and who came for repetitive mammography after abnormal mammography and depression levels were found to be similarly high in women at the first and repeated mammographies [18]. Was reported that women who were followed up after the diagnosis of benign breast disease experienced intense stress [19]. Although the results of most of the studies in the literature are parallel with the results of our study, Fairbanks, et al. found that there was no significant difference between anxiety and depression levels of healthy women and women with benign breast disease [20].

The increase in the duration of fibrocystic disease of breast in the study negatively affected the psychosocial health status of women. This may be due to an increase in the number of examinations for follow-up caused by the duration of the disease.

Women with fibrocystic breast disease may have a negative impact on their psychosocial well-being compared to healthy women, that they have more frequent breast checks, that the tests are painful, and that breast cancer stories in women of the sample group are higher than healthy women.

Sexual health is an important health component [11]. Sexual health can negatively be affected by the factors such as chronic illnesses, pain, changes affecting body sensation, anxiety, depression and stress [21]. In addition, because the breast expresses femininity, attractiveness, fertility and sexuality, any disease, fear of loss or loss can negatively affect sexual life [22,23]. It has been determined in the study that the duration of fibrocystic disease of breast negatively affects the level of sexual life quality. Negative effects of psychosocial health level as the duration of the disease increases and pain caused by hormonal changes in the premenstrual period are thought to have adversely affected sexual life quality. 


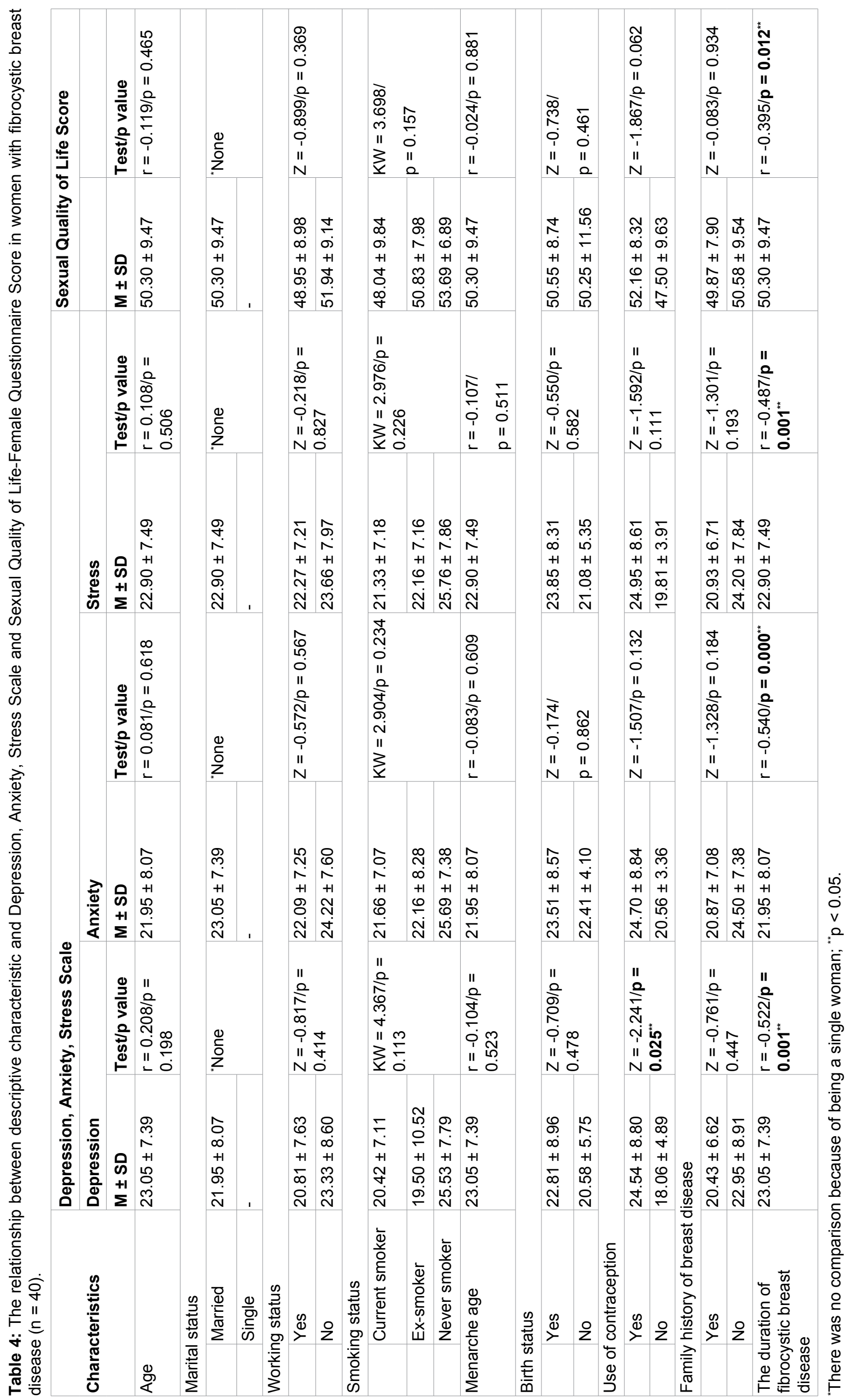


It has been found that women with fibrocystic breast disease have moderate levels of sexual life quality and women with fibrocystic breast disease have lower levels of sexual life quality than women without fibrocystic breast disease. Bukovic, et al. found that $36.27 \%$ of women with benign breast disease and $51.76 \%$ of women with malign breast disease had sexual problems. In the same study, it was reported that body senses were negatively affected in both groups, regardless of whether the disease was malign or benign [24]. However, in a study in which sexual health was assessed for women with benign breast disease and healthy women, no difference was found in sexual dysfunction between the two groups [20].

Many physical and psychological factors can affect sexual health. Pain in fibrocystic breast patients and poor psychosocial health status may have adversely affected sexual life quality. This is important in order to demonstrate the need for women with fibrocystic breast disease to be assessed for their sexual life in their later life.

\section{Conclusion}

Women with fibrocystic breast disease were found to have higher levels of depression, anxiety, stress and lower levels of sexual life when compared with healthy women. Women with fibrocystic breast disease are often exposed to psychosocial problems due to cancer risk. In this respect, informing the health professionals about the perception of the individual risk towards women, evaluating the psychosocial needs of women with real risk, providing information in this direction, and providing sexual health, emotional and social support can contribute to the psychosocial well-being and raising the quality of sexual life.

\section{References}

1. Unal H (2001) Selim Breast Diseases. In: Unal G, Unal H, Breast diseases. ( $1^{\text {st }}$ edn), İstanbul: Nobel Medical Bookstore, 167-188.

2. Schnitt S, Connolly J (2004) Pathology of benign breast disorders. In: Harris JR, Lippman ME, Morrow M, Diseases of the Breast. ( $3^{\text {rd }}$ edn), Philadelphia: Lippincott Williams and Wilkins, 1265-1296.

3. Stanton AL, Snider PR (1993) Coping with a breast cancer diagnosis: A prospective study. Health Psychol 12: 16-23.

4. Ubhi SS, Wright S, Clarke L, Black S, Shaw P, et al. (1996) Anxiety in patients with symptomatic breast disease: Effects of immediate versus delayed communication of results. Ann R Coll Surg Engl 78: 446-469.

5. Deane KA, Degner LF (1998) Information needs, uncertainty, and anxiety in women who had a breast biopsy with benign outcome. Cancer Nurs 21: 117-126.

6. Howard RA, Harvey PG (1998) A longitudinal study of psychological distress in women with breast symptoms. J Health Psychol 3: 215-226.

7. Absetz P, Aro AR, Sutton SR (2003) Experience with breast cancer, pre-screening perceived susceptibility and the psychological impact of screening. Psychooncology 12: 305318 .
8. Meechan GT, Collins JP, Moss-Morris RE, Petrie KJ (2005) Who is not reassured following benign diagnosis of breast symptoms? Psychooncology 14: 239-246.

9. Van Lankveld J, Laan E (2009) Scientific research on sexuality. In: Gijs L, Gianotten W, Vanwesenbeeck I, Weijenborg P, Seksuologie [Sexology]. Bohn Stafleu van Loghum, Houten, 45-67.

10. Pool G, Van de Wiel HBM, Jaspers JPC, Weijmar Schultz WCM, Van Driel MF (2008) Cancer. In: Gianotten WL, Meihuizen-de Regt MJ, Van Son-Schoones N, Sexuality with disease and physical disability. Van Gorcum, Assen, 325-339.

11. Krebs LU (2012) Sexual health during cancer treatment. Adv Exp Med Biol 32: 61-76.

12. Akin A, Cetin B (2007) The depression anxiety and stress scale (DASS): The study of validity and reliability. Educational Sciences: Theory and Practice 7: 260-268.

13. Tugut N, Golbasi Z (2010) A validity and reliability study of Turkish version of the Sexual Quality of Life Questionnaire-Female. Cumhuriyet Medical Journal 32: 172-180.

14. Eskelinen M, Ollonen P (2011) Assessment of general anxiety in patients with breast disease and breast cancer using the spielberger STAI self evaluation test: A prospective case-control study in Finland. Anticancer Res 31: 1801-1806.

15. Iwamitsu Y, Shimoda K, Abe H, Tani T, Okawa M, et al. (2005) Anxiety, emotional suppression, and psychological distress before and after breast cancer diagnosis. Psychosomatics 46: 19-24.

16. Cunningham LL, Andrykowski MA, Wilson JF, McGrath PC, Sloan DA, et al. (1998) Physical symptoms, distress and breast cancer risk perceptions in women with benign breast problems. Health Psychol 17: 371-375.

17. Lou Z, Li Y, Yang Y, Wang L, Yang J (2015) Affects of anxiety and depression on health-related quality of life among patients with benign breast lumps diagnosed via ultrasonography in China. Int J Environ Res Public Health 12: 10587-10601.

18. Keyzer-Dekkera CMG, Vries JD, Esch L, Ernst MF, Nieuwenhuijzene GA, et al. (2012) Anxiety after an abnormal screening mammogram is a serious problem. Breast 21: 83-88.

19. Andrykowski MA, Carpenter JS, Studts JL, Cordova MJ, LC Cunningham L, et al. (2002) Psychological impact of benign breast biopsy: A longitudinal, comparative study. Health Psychol 21: 485-494.

20. Fairbanks F, Andres MP, Caldeira P, Abdo C, Podgaec S (2017) Sexual function, anxiety and depression in women with benign breast disease. A case-control study. Rev Assoc Med Bras (1992) 63: 876-882.

21. Clayton A, Ramamurthy S (2008) The impact of physical illnesses on sexual dysfunction. Adv Psychosom Med 29: 70-88.

22. Yılmazer N, Aydiner A, Ozkan S, Aslan I, Bilge N (1993) Comparison of body image and self esteem in total mastectomy and breast conserving treatment. Turkish Oncology Journal 8: 1449-1453.

23. Onen-Sertoz O, Elbi-Mete H, Noyan A, Alper M, Kapkac M (2004) Effects of surgery type on body image, sexuality, self-esteem, and marital adjustment in breast cancer: A controlled study. Turk Psikiyatri Derg 15: 264-275.

24. Bukovic D, Fajdic J, Strinic T, Habek M, Hojsak I, et al. (2004) Differences in sexual functioning between patients with benign and malignant breast tumors. Coll Antropol 28: 191-201. 